\title{
EMENDATIONES TACITEAE.
}

FASCICULUS PRIMUS.

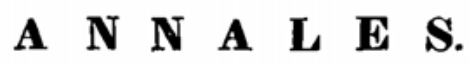

SCRIPSIT

\section{RAIMUNDUS SEYFFERT.}

\section{BEROLINI.}

TYPIS ET IMPENSIS G. REIMERI.

MDCCCXLIII. 



\section{VIRO ILLUSTRISSIMO}

\section{CAROLOCORTÜM}

PHILOS. DOCTORI,

REGI A CONSILIS REgIMINIS INTIMIS, EQVITI ETC. ETC.

PUERITIAE RECTORI, IUVENTAE FAUTORI PIO

GRATOQUE ANIMO COLENDO

J). D. D.

SCRIPTOK. 
